\title{
GAMIFICATION AND ACTIVE METHODOLOGIES AT UNIVERSITY: THE CASE OF TEACHING LEARNING STRATEGY IN LAW
}

\author{
Daniela Serra Castilhos \\ Portucalense University (PORTUGAL)
}

\begin{abstract}
The "gamification" is a strategy to use elements of the games outside the environment of games and can be applied as a teaching strategy. The application in the classroom as an active learning strategy is still a great challenge for education, especially in higher education in such a traditional context, as is the case with Law teaching. The present paper reports a case study on how it was applied a quiz using the kahoot platform as teaching learning strategy in the discipline Constitutional Law in a university in Portugal. The results showed that kahoot enhanced the use of gamification in the classroom by facilitating the use of elements of games such as immediate feedback, clear rules, and brings fun, pleasure and motivation. Students allude to competition as stimulus for learning and they realized the kahoot can be used as a replacement for traditional classroom once you can reach different levels of complexity that challenge students and make learning more efficient and durable. We conclude that the technique, however, presents some limitations. The perception and interests of students was a positive result from the experience.
\end{abstract}

Keywords: Gamification, Kahoot, active learning.

\section{INTRODUCTION}

Active learning methodologies are based in the decentralization of the professor function in classroom. A transition for a student-centered learning is expected whereas professors could plan different approaches for learning effectiveness.

The active learning methodology, known as Gamification, allow to combine content, game and technology aiming to motivate the learning experience in a classroom. According to Ribeiro et al [1] this methodology aims to enhance the student learning experience, introducing an alternative to class management and traditional evaluation methods, getting students' attention through gamified activities with goals and rankings in a collaborative environment.

Gamification represents such a challenge for teachers serving in Higher Education institutions as it is becoming a trending topic in education [2]. Although gamification is not limited to the use of technology-driven games for educational purposes (for example, educational video games in the shape of serious games), educational video games account for a high percentage of all gamification efforts in education. [2]

Prensky [3] distinguishes "Digital Natives" of "Digital Immigrants". Today's students are no longer the people our educational system was designed to teach, because they represent the first generation to grow up with this new technology.

The teachers need to reform instructional methods and delivery of class lectures to compensate, to the degree possible, for differences in academic ability and motivation among students as proposed by Ohno et al [4] active learning is a method with possible utility in implementing a paradigm shift from a passive and unidirectional approach to lecture design to a proactive and interactive orientation.

\section{METHODOLOGY}

The present paper reports a case study on it was applied a quiz using the kahoot platform as teaching learning strategy in the discipline Constitutional Law in a university in Portugal.

In order to engage the undergraduate law students in class, it was decided to apply an active learning methodology during practical classes in Constitutional Law. Within the class planning, it was chosen to use this technique on the 7th week of class, which corresponds to the review of the subject for a 1st exam, when the students would have already had some control over the content, because they would be evaluated the following week. 
Kahoot! is a popular eLearning tool that can easily be used to add vitality, student engagement, and meta-cognitive supports to higher education classrooms with limited instructor or student training required. The free online learning platform has gained wide acceptance globally with more than 30 million users worldwide, and it is based on current user-centered and behavioral design methodologies. [5]

The professor elaborated a quiz comprised of 20 true and false questions of alternatives between were elaborated. It was applied in three practical classes in which were attended by a total of 60 students, distributed in groups of 23, 22 and 25 elements. All students used their own mobile devices. The following image shows the basic structure of a question using kahoot:

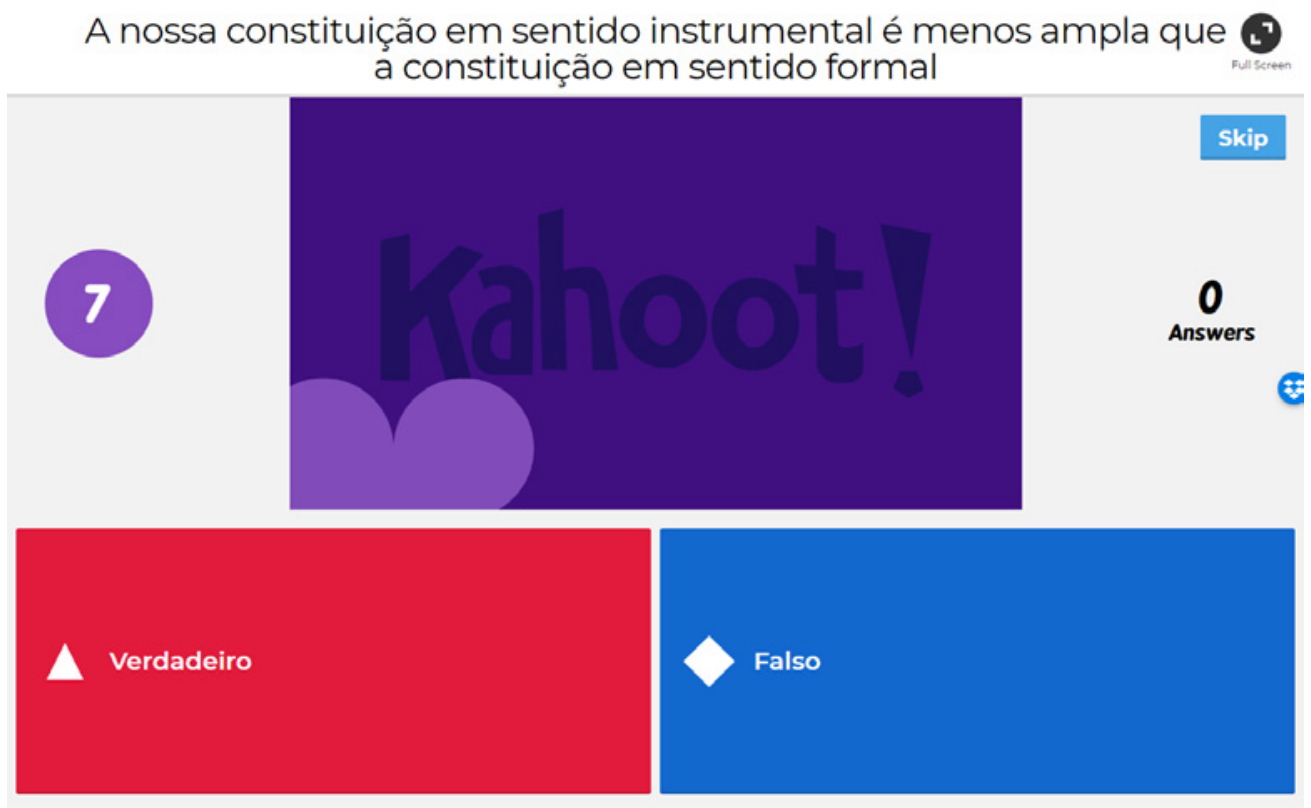

Figure 1. Caption for the Kahoot's question.

With each question answered, according to the results, the teacher explained the answer in more detail. The students were extremely enthusiastic. To increase students' interest and competition among them, they were informed that the student who obtained the best result would receive a symbolic prize (chocolate).

The assessment of the experience was obtained from anonymous write narratives submitted by the students in the end of classes. These narratives were analyzed with qualitative methodology.

\section{RESULTS}

The data were collected through a questionnaire applied to students in order to evaluate the didactic proposal. The results obtained were positive concerning to the students' motivation in the use of the collaborative tools and the contribution in the teaching process.

The use of Kahoot allow immediate and frequent feedback, which provides opportunities for professor to tailor their instruction based on student understanding on quizzes. The importance of feedback that was demonstrated in the research of Kapp [6] was also felt by the students themselves. We can observe it by the expressed comment: "In the same class I was able to see the points of the subject I had already memorized, it was excellent for a revision class".

Furthermore, Hanus \& Fox [7] consider that tailors difficulty progression that facilitates scaffolded instruction based on each individual student's needs. This advantage was expressed in the comment "Very good and interesting! It allows a greater perception of what is known or not and still gives us chance to clarify. I like it!"

Camilleri et al regard that gamification encourages motivation through competition (e.g. through leaderboards). [8] The comments of the students were in the same sense, for example: "I found this exercise very useful as a means of learning and particularly enjoyed the competitive aspect and how it 
captivates the students. It joins the useful to the pleasant, I must say that I quite liked the idea and I would not mind repeating it. "

According to Hanus \& Fox [7] the gamification tailors difficulty progression that facilitates scaffolded instruction based on each individual student's needs.

This type of class gives students the freedom to fail without fear when learning [9] as was shown in the comments "I think that these classes are more productive, because they allow a greater interaction with the students and also contribute to the clarification of doubts in a more spontaneous way".

A word frequency analysis revealed that the most commonly used terms by students were "motivation" and "fun". In addition, most students spontaneously expressed that it would be desirable to repeat this type of class more often, some deemed it as an evolution of teaching.

The students cited the competition as stimulus for learning and they realized the kahoot can be used as a replacement for traditional classroom once you can reach different levels of complexity that challenge students and make learning more efficient and durable

\section{CONCLUSIONS}

The results showed that kahoot enhanced the use of gamification in the classroom by facilitating the use of elements of games such as immediate feedback, clear rules, fun, pleasure and motivation. Students cite competition as stimulus for learning and they realized the kahoot can be used as a replacement for traditional classroom once you can reach different levels of complexity that challenge students and make learning more efficient and durable.

The students were greatly motivated thanks to the participative, active and collaborative environment resulting from the developed approach. These circumstances, where the good atmosphere in the classroom stands out, have favored learning.

We conclude that the technique, however, presents some limitations. For example, the application only allows the use of a few characters in the creation of the questions, making it impossible to elaborate more complex questions common to a legal course. On the other hand, it is applicable if all have digital devices available with the same degree of digital access.

Previous research also found that lack of expertise in applying new methodologies or lack of resources are common barriers for teachers when applying technological innovations in the classroom (Mumtaz, 2000).

We argue that this approach, together with gamification elements, is helpful in increasing the students' motivation, besides improving the learning experience and performance.

The perception and interests of students were very positive from the experience. It was surprising for the professors that the unanimity of the students considered a great methodology, and a substantial part asked to have more classes using this methodology.

However, we can consider it as a work in progress because it is necessary to repeat the experimentation to obtain more precise conclusions.

\section{REFERENCES}

[1] L. Ribeiro, T. Silva and A. Mussi, "Gamification: a methodology to motivate engagement and participation in a higher education environment," International Journal of Education and Research, pp. 249-264, April 2018.

[2] A. Martí-Parreño and J. Sánchez-Mena, "Drivers and Barriers to Adopting Gamification: Teachers' Perspectives," EJEL The Electronic Journal of e-Learning, p. 434-443, October 2017.

[3] M. Prensky, "Digital Natives, Digital Immigrants Part 1," On the Horizon, vol. 9, no. 5, pp. 1-6, 2001.

[4] A. Ohno, T. Yamasaki and K. Tokiwa, "A discussion on introducing half-anonymity and gamification to improve students' motivation and engagement in classroom lectures," in 2013 IEEE Region 10 Humanitarian Technology Conference, Sendai, 2013. 
[5] C. La Rosa and J. Pump, "Using Kahoot! in the Classroom to Create Engagement and Active Learning: A Game-Based Technology Solution for eLearning Novices," Management Teaching Review, pp. 151-158, 22.

[6] K. Kapp, The gamification of learning and instruction: Game-based methods and strategies for training and education, San Francisco: Pfeiffer, 2012.

[7] M. D. Hanus and J. Fox, "Assessing the effects of gamification in the classroom: A longitudinal study on intrinsic motivation, social comparison, satisfaction, effort, and academic performance," Computers \& Education, vol. 80, pp. 152-161, 2015.

[8] V. Camilleri, L. Busuttil and M. Montebello, "Social interactive learning in multiplayer games," in Serious games and edutainment applications, London, Springer, 2011, pp. 481-501.

[9] J. Hamme and J. Lee, "Gamification in Education: What, How, Why Bother?," Academic Exchange Quarterly, vol. 15, no. 2, 2011. 